\title{
A Conceptual Framework on IT Infrastructure Flexibility as Determinant of Strategic Utilization of Information Systems
}

\author{
Norizan Anwar \\ Faculty of Information Management \\ Universiti Teknologi MARA (UiTM) \\ Shah Alam, Selangor, Malaysia
}

\author{
Mohamad Noorman Masrek \\ Accounting Research Institute \\ Universiti Teknologi MARA (UiTM) \\ Shah Alam, Selangor, Malaysia
}

\begin{abstract}
The strategic benefits of computer based information systems have been well documented in the literature. In the same light, researchers have also unveiled various factors that promote strategic uses of computer based information systems. Among the identified factor is information technology infrastructure flexibility (ITIF). However, previous studies focusing on the contribution of information technology infrastructure flexibility towards strategic uses of information systems is limited in terms of scope and coverage. Defining information technology infrastructure flexibility as the composite relationship of Human IT Infrastructure, Technical IT Infrastructure and Process IT Infrastructure, this proposes a conceptual framework linking ITIF towards strategic use of information systems.
\end{abstract}

\section{Introduction}

The term information systems denote different meaning to different people. People within the IT field has always equated and understood information systems to computerbased information systems. Many ICT textbooks has defined computer based information systems (hencefort, addressed as IS) as the combination of hardware, software, people and procedure. Seddon presented a broad definition of IS as "either some aspect of an application of IT, one individual application, a group of applications including those of an entire organization) or an application of one type of IT" [1]. Accordingly, classified IS as (i) an aspect of IT use (e.g., a single algorithm or form of user interface), (ii) a single IT application (e.g., a spreadsheet, a PC, or a library cataloguing system), (iii) a type of IT or IT applications (e.g., TCP/IP, a group decision support systems or GDSS, a transaction processing system or TPS, a data warehouse etc.), (iv) all IT applications used by an organizations of sub-organizations, (v) an aspect of a system developing methodology, (vi) the IT function of an organization or sub-organizations [2].

In general, IS are used for improving effectiveness and efficiency of the operation on business operation in achieving their mission and vision. With the use of IS, business organization becomes more effective, efficient, productive and able to increase their productivity and profitability. In essence, IS can be considered basic necessity for supporting business transaction. Every management level in an organization will require IS. For example, in a typical organizational setting, the operational level will Transaction Processing System (TPS); the tactical level will use Management Information System (MIS); while the strategic level will use IS such as Enterprise Information System (EIS), Enterprise Support System (ESS) etc.

The continued advancement and sophistication of ICT has resulted into blurring the demarcation between various IS, such as TPS, MIS, DSS, ESS etc.. Nowadays, one single IS, for instance the ERP, can accommodate all the criteria of all different IS i.e. TPS, MIS, DSS, ESS etc. In other words, single IS can actually consist of TPS, MIS, DSS, ESS etc. This type IS can fulfill the requirements for supporting operational, tactical and strategic activities in the organization. The literature has stressed the importance of having strategic plans in long terms planning towards achieving business goals and missions. In order to support the implementation of the strategic plan, organization has its own strategic information systems planning (SISP). Through this SISP, 
various IS will be identified to be exploited for the purpose of supporting the strategic goals. Many evidences showed that when organization exploited or used IS for strategic purposes, the efficiency and effectiveness of the organization is greatly improved and most importantly, the revenue and profit is also increased.

Despite the existence of several evidences and claims that the use of IS for strategic purpose helped to improve the productivity and efficiency of the organizations, it is still really unknown whether such practices are also prevailing the context of Malaysian companies. Researchers have suggested that, focusing on several factors such as organizational factors, technological factors and environmental factors will help to increase IS strategic use [3] [4] [5]. Within the technological factors, the ITIF is also being listed as one of the critical contributors [3] [4] [5] [6] [7] [8] [9] [10] [11] [12] [13] [14]. However, empirical evidence supporting this claim is very scarce or limited. The available literature is only in the form of conceptual framework and still not fully tested empirically [15].

Therefore, the objective of this paper is to explore the ITIF as the determinant of strategic use of information system. Further elaborations will be discussed in the next sections. Section I discusses the introduction of IS strategic use. Section 2 discusses the proposed conceptual framework of this study. Section 3 and 4 discuss the literature review of dependent variables and independent variables and the last section presents the conclusion of this paper.

\section{The Proposed Conceptual Framework}

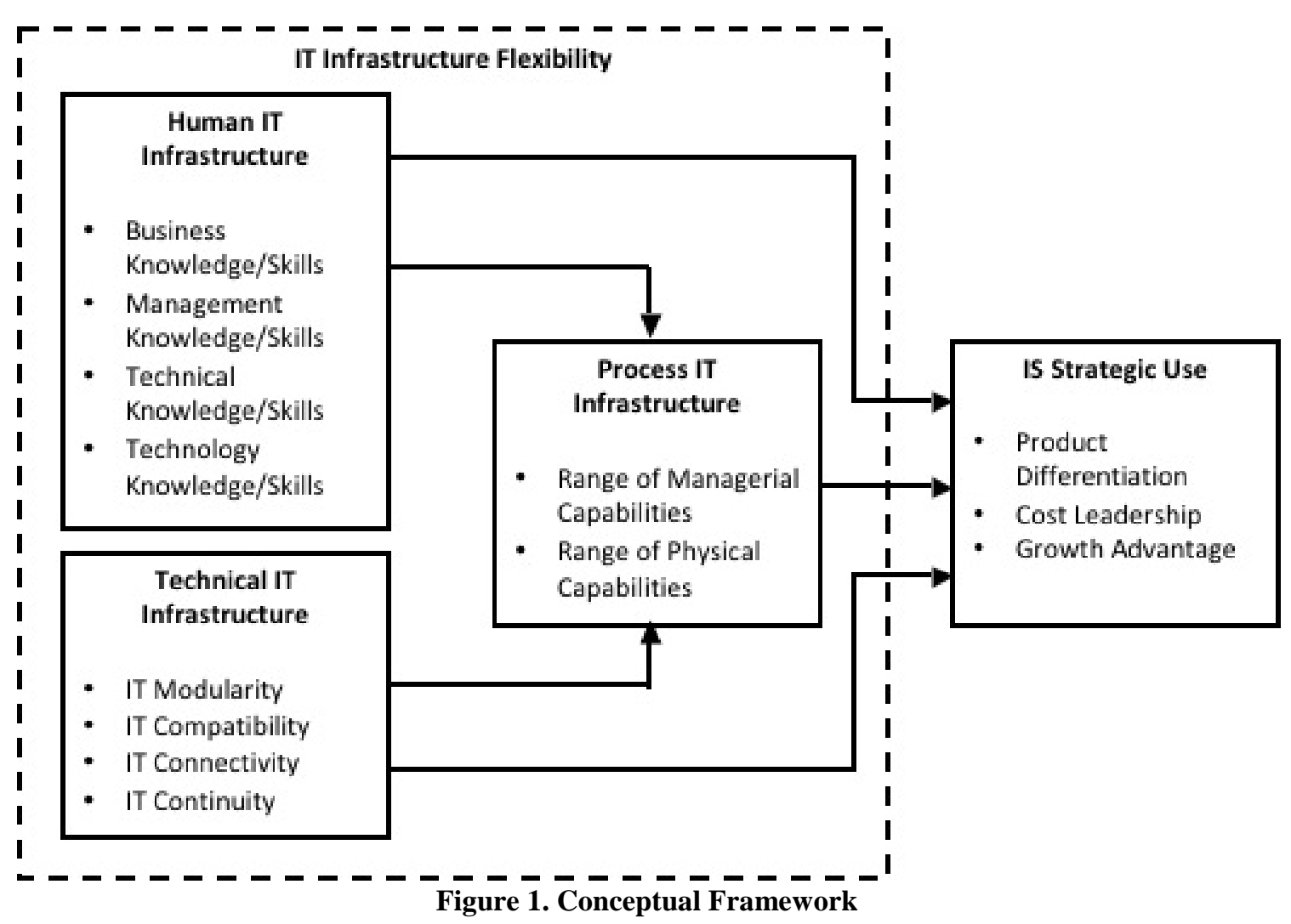

Figure 1 presents the proposed framework for investigating the relationship between IT infrastructure flexibility and strategic use of IS. The framework is conceptualized from the previous studies conducted [3] [4] [5] [6] [7] [8] [9] [10] [11] [12] [13] [14] [15] [16] [17] [18]. The dimensions of strategic use of IS are product differentiation, cost leadership and growth advantage. Meanwhile, the dimensions of IT infrastructure flexibility are Human, Technical and process IT infrastructure.

IS researchers have empirically showed that IT infrastructure flexibility has influence on IS effectiveness [10] [11] [12] [13] [14] [15]. 
DeLone developed a model for measuring IS effectiveness [19] [20]. The model had received favorable attention by many IS researchers. The model has included usage or utilization as one of the construct for measuring effectiveness. However, DeLone cautioned that when measuring usage or utilization, researchers should focus on the extensiveness or depthness of the usage [20]. To this effect, we argue that measuring IS for strategic use fulfilled the requirements set [20]. Accordingly the following propositions are established:

P1: Process IT infrastructure has a positive relationship with IS strategic use.

P2: Human IT infrastructure has a positive relationship with IS strategic use.

P3: Technical IT infrastructure has a positive relationship with IS strategic use.

Fink conceptualized that relationship exists amongst the IT infrastructure flexibility dimensions [5]. Their study identified three (3) dimensions of IT infrastructure flexibility as consisting of Human IT infrastructure; Technical IT infrastructure and Process IT infrastructure. Their study empirically showed that several dimensions from Human IT infrastructure and Technical IT infrastructure have a significant relationship with Process IT infrastructure. Drawing upon these findings, we developed the following propositions:

P1: Technical IT infrastructure has a positive relationship with Process IT infrastructure.

P2: Human IT infrastructure has a positive relationship with Process IT infrastructure.

\section{IS Strategic Use}

The strategic use of IS has made business organization to enjoy many great benefits and advantages. Compiling form various empirical literature, synthesized the strategic benefits of IS are as shown in Table 1 [21].

Table 1. Classification of the Benefits of IS Strategic Planning adapted from [21]

\begin{tabular}{|c|c|}
\hline Focus on benefits & Strategic Benefit \\
\hline \multirow{16}{*}{ Strategic } & Support decision-making process \\
\hline & Increase organizational efficiency \\
\hline & Improve open culture of organization \\
\hline & Enable users \\
\hline & Increase productivity of employees \\
\hline & Support coordination of work \\
\hline & Reduce costs \\
\hline & Interface and support different organizational levels \\
\hline & Improve growth and success \\
\hline & Create new strategic opportunities \\
\hline & Increase quality \\
\hline & Offer new strategic options \\
\hline & Support reactions to change \\
\hline & Support organizational teamwork \\
\hline & Increase Organizational effectiveness \\
\hline & Support collaboration and sharing of information \\
\hline \multirow[t]{12}{*}{ Competitiveness } & Develop/produce new market \\
\hline & Develop/produce new product/services \\
\hline & Obtain competitive advantage \\
\hline & Increase organizational competitiveness \\
\hline & Display market leadership \\
\hline & Support innovation \\
\hline & Increase customer service and satisfaction \\
\hline & Become a leader in new technology \\
\hline & Improve relationships with customers \\
\hline & Enhance competitive advantage \\
\hline & Improve market share \\
\hline & Become responsible locally (markets, government) \\
\hline Alignment & Integrate IS strategic plan into business strategic plan \\
\hline
\end{tabular}




\begin{tabular}{|l|l|}
\hline Focus on benefits & Strategic Benefit \\
\hline \multirow{y}{*}{} & Improve relationships with suppliers \\
\cline { 2 - 3 } & Improve resource control \\
\cline { 2 - 3 } & Integrate or become independent of IS function \\
\cline { 2 - 3 } & Improve global efficiency \\
\cline { 2 - 3 } & Support global organization \\
\cline { 2 - 3 } & Attain global alliance \\
\cline { 2 - 3 } & Improve resource creativity \\
\cline { 2 - 3 } & Improve resource flexibility \\
\cline { 2 - 3 } & Improve resource learning \\
\cline { 2 - 3 } & Create standards \\
\cline { 2 - 3 } & Improve knowledge \\
\cline { 2 - 3 } & Compose by integrating smaller systems \\
\cline { 2 - 3 } & Support learning transfer \\
\hline
\end{tabular}

\section{Cost Leadership}

Cost leadership strategy is concerned with the use of IS to help business organization to reduce operating cost. Masrek described cost leadership is about the use of IS maintain low costs in production and distribution within the industry [15]. In the context of Malaysia, with the motto "everyone can fly", Air Asia is well known as a cheap flight. It is quite apparent that, Air Asia has exploited the use of IS in embracing the cost leadership strategy. All booking transactions, printing of flight details and check-in process, etc. are done via online or self-service [23]. This makes Air Asia able to offer their customers with free, cheap and attractive price.

\section{Product or Service Differentiation}

Product or service differentiation strategy is where the organization able to produce and offer their respective customer with a different product or service available in the market. Through the use of IS, business organization can developed or design product or services that really fulfill customers needs. Various forms of IS can be used to conveniently collect customers' requirements and expectations. Through online survey, feedbacks of the customers can be used to enhance the quality of the products or services. Today, it is already very common for organizations to capture customers requirements and expectations through this approach.

\section{Growth Advantage}

Growth advantage strategy is about using IS to extend the existing products or services available on shelf. This strategy also suggests that business organization can expand and market their products or services beyond the traditional and conventional ways. For instance, through the use of e-commerce or m-commerce, embedded with
Marketing Information Systems or Customer Relationship Management, business organization can extend their sales coverage beyond their geographical boundaries. The customers' profile and their buying or purchasing trends, obtained in the systems can be analyzed to make predictions. An example of successful ecommerce systems reported in the context of Malaysia include Mudah.com, Zalora.com [24].

\section{IT Infrastructure Flexibility}

IT infrastructure has always been considered to be the foundation of shared IT capabilities that enable the development of IT applications and the support of business processes [25]. Against this premise, a defined IT infrastructure as "IT resources and organizational capabilities that are shared across the organization and that provide the foundation on which IT applications are developed and business processes are supported" [25]. Accordingly, an effective IT infrastructure must be flexible and robust [26]. Thus, flexible IT infrastructure as stated is the ability of existing IT infrastructure to adapt changes from both internal and external of the organization in order to facilitate information sharing, system development and the continuity of IT operations with minimal effort and time [8]. Byrd stated that IT infrastructure flexibility is the ability to easily and readily diffuse or support a wide variety of hardware, software, communications technologies, data, core applications, skills and competencies, commitments, and values within the technical physical base and the human component of the existing IT infrastructure [3]. Accordingly, Byrd developed an instrument for assessing IT infrastructure flexibility which consists both technical and human components [3]. 
Byrd explained that the technical infrastructure is the choices pertaining to applications, data, and technology configurations while the human infrastructure is the choices pertaining to the knowledge and capabilities required to manage effectively the IT resources within the organization [3]. Fink identified additional component of IT infrastructure flexibility as process IT infrastructure [5]. Drawing from the process oriented approach, Fink argued that the process element frequently corresponds to share IT services provided by IT [5]. Therefore, theses processes should also be viewed as part of IT infrastructure and must be flexible, similar to the technical and human components.

The technical component flexibility consists of four dimensions: IT connectivity, application's functionality, IT compatibility, and data transparency. The human component flexibility consists also four dimensions which are technology management knowledge/skills, business knowledge/skills, management knowledge/skills, and technical knowledge/skills. Many researchers have adapted the instrument developed by Byrd when measuring IT infrastructure flexibility [3] [5] [8] [10] [16] [27]. Besides the four dimensions, IS researchers have also introduced rapidity, modernity and continuity as additional dimensions of technical component flexibility [27]. The dimensions of process IT infrastructure as identified by Fink are (i) range of managerial capabilities and (ii) range of physical capabilities [5].

IT infrastructure flexibility has influence and gives a huge impact on the strategic use of IS. The flexibility of human, technical and process of IT (hardware, software, network etc.) structure is crucial and important as IS used is unpredictable. The adjustment, modification, etc. of IT infrastructure may come whenever required. Thus, the above mention dimensions directly influence the strategic use of IS. In the context of this study, we choose these three (3) dimensions as have been used and tested [3] [4] [5]. These dimensions are also consistent with previous studies done and a few studies with additional of scalability, continuity, rapidity, facility and modernity [6] [10] [12] [13] [14] [27] [28] [29] [30]. However, those nine (9) may not cover all contexts of IT structure (hardware, software, network, data $\&$ human).

\section{Human IT Infrastructure}

Synthesizing from various literature, Byrd suggested that the human IT infrastructure flexibility consists of four dimensions which are (i) technology management knowledge / skills (ii) business knowledge/ skills (iii) management knowledge / skills, and (iv) technical knowledge / skills [3].

The technology management knowledge and skills focus on the understanding of where and how to deploy IT effectively and profitably by meeting the strategic goals and objectives of an organization [3]. New technology introduced almost everyday. Each of the technologies usually offers the extra advantage towards one another. The IT personnel must be able to identify which technology works very well with which IS used. The ability to understand the functionality of both is important. It is no use if the technology is up-to-date, but the IS only need basic specifications.

Business functional knowledge and skills relates to the ability to interpret business problems and develop appropriate technical solutions. Interpersonal and management knowledge and skills include abilities like planning, organizing, writing, teaching, and leading [3]. Accommodate every each angle of business requirement, objective, mission and vision is necessary for IT personnel in developing or choosing the right IS to be used. The IS must be able to minimize the use of men power and resources within the organization. External client needs also need to be considered.

Management knowledge and skills is the ability to plan, organize, and lead projects; plan, organize, and write clear, concise, effective memos, reports, and documentation; be sensitive to organizational culture and politics; and execute work in a collaborative environment [3]. The IT personnel skills are beyond on technology matters. This also has been agreed where an IT personnel competency must include both the skills and experience to perform IT activities [8]. The structure and process in the organization must be catered.

Technical specialty knowledge and skills cover the knowhow and skills in technical areas, such as computer operating systems, relational databases, telecommunications, and other such areas [3]. The advancement movement of technology is very rapid. The IT personnel must able to accommodate themselves to any of the technology. In one extend, the IT personnel must 
be able to handle current IS to be used in different platform of operating systems. Training, exhibition etc. is required and necessary for them to get latest information regarding those products in the market. For example, Oracle will invite their existing client to a brief introduction to any of their new product/services.

\section{Technical IT Infrastructure}

Technical IT infrastructure is how flexible enough of hardware, software and network technologies to accommodate new, changes or additional one of those technologies in information system settings. In this study, four dimensions have been identified, namely, modularity, compatibility, connectivity and continuity.

Modularity is the ability to add, modify, and remove any software, hardware, or data components can be either seamlessly or effortlessly diffused into infrastructure with ease and no major overall effect [3]. However, Chung define modularity as it applies to the key resource of IT where it is similar to the term "flexibility" in the manufacturing strategy literature [10].

Compatibility is the ability to share any type of information (text, voice, image and video) across any technology component [3] [4] [8] [16]. Information captured in IS may consist several formats and forms. Different departments within the organization may use the same information. The consistency of using the same platform of hardware and software varies according to the job function. Therefore, whenever the information is required and needed, it is compatible in term of formats and forms without requiring a converter program / software to translate this information to become readable.

Connectivity refers to the ability of any technology attached to any other technology components. It means that every person, every functional area, and every application in the organizations are linked to one another [16]. Connectivity is related to the network infrastructure within the organization and also with their customers. The sharing of data across different geographical areas required good network connectivity. Besides, any breakdown of the IS outside the organization, the IT personnel may do troubleshooting remotely without need to go to the side area.
Continuity is the degree to which either hardware or software or data or even IT personnel can seamlessly serve the users in an organization without disruption [8]. Continuity suggests that even the hardware or software components are being replaced, the IS must be able to work as usual without interruptions and disruption. The IS might be down for a few hours during data migration, hardware replacement etc. but not a few days.

\section{Process IT Infrastructure}

Process IT infrastructure involves the range of management and physical capabilities are extended [5]. The process IT infrastructure is related to internal characteristics while the range of management is where the power and cooperative among the management level to proposed/suggest, approved and support any proposal related to IT infrastructure improvement. Range of physical is the flexibility of the organization to agile their organization structure in order to accommodate the IT infrastructure adjustment, addition or no longer use.

\section{Summary}

The conceptual framework proposed in this paper provides an opportunity for empirical study investigation in future. Therefore, in order to test the framework and the corresponding preposition, the researcher plans to conduct survey research involving the Multimedia Super Corridor (MSC) status companies in Klang Valley. The target area would be the state of Selangor and Federal Territory Kuala Lumpur, Malaysia. Furthermore, it targeted to cover the four (4) clusters in MSC status. Potential researchers who are interested to adopt the framework can also consider testing the model in other setting besides the MSC status companies.

\section{Acknowledgements}

We greatly appreciate the Ministry of Higher Education (MOHE) and the Research Management Institute (RMI), UiTM for funding the research project [ref. no. 600-RMI/RAGS 5/3 (142/2012)].

\section{References}

[1] Seddon, P. B. "A respecification and extension of the DeLone and McLean model of IS success," Information Systems Research, 8(3), 240-253, 1997. 
[2] Seddon, P.B., Staples, S., Patnayakoni, R. \& Bowtell, M. "Dimensions of Information System Success," Communications of the Association for Information Systems, 2 (3), 1999.

[3] Byrd, T. A. \& Turner, D. E. "Measuring the Flexibility of Information Technology Infrastructure: Exploratory Analysis of a Construct," Journal of Management Information Systems, 17(1), 167-208, 2000.

[4] Byrd, T. A. \& Turner, D. E. "An Exploratory Analysis of the Information Technology Infrastructure Flexibility Construct," Information \& Management, 39, 41-52, 2001.

[5] Fink, L. \& Neumann, S. "Exploring the perceived business value of the flexibility enabled by information technology infrastructure," Information \& Management, 46, 90-99, 2009.

[6] Duncan, N.B. "Capturing flexibility of information technology infrastructure: a study of resource characteristics and their measure," Journal of Management Information Systems, 12(2), 37-57, 1995.

[7] Chung, S. H., Rainer, R. K. Jr. \& Lewis, B. R. "The impact of information technology infrastructure flexibility on strategic alignment and applications implementation," Communications of the Association for Information Systems, 11, 191-206, 2003.

[8] Chanopas, A., Krairit, D. \& Khang, D. B. "Managing information technology infrastructure: a new flexibility framework," Management Research News, 29(10), 632-651, 2006.

[9] Zhang, J., Li, H. \& Ziegelmayer, J. "Resource or capability? A dissection of SMEs' IT infrastructure flexibility and its relationship with it responsiveness," Journal of Computer Information Systems, 46-53, 2009.

[10] Chung, S. H. et al. "An empirical study of the relationships between IT infrastructure flexibility, mass communication and business performance," The database for advances in Information Systems, 36(3), 26-44, 2005.

[11] Bush, A. A., Tiwana, A. \& Rai, A. "Complementarities Between Product Design Modularity and IT Infrastructure Flexibility in ITEnabled Supply Chains," IEEE Transactions on Engineering Management, 57(2), 240-254, 2010.

[12] Sirkemaa, S. "IT infrastructure management and standards," Proceedings of the International Conference on Information Technology: Coding and Computing (ITCC'02), 2002.

[13] Bhatt, G. et al. "Building and leveraging information in dynamic environments: The role of IT infrastructure flexibility as enabler of organizational responsiveness and competitive advantage," Information \& Management, 47, 341-349, 2010.

[14] Gholami, B. Kaviani, F. \& Zabihi, E. "Web 2.0, a Boost in IT Infrastructure Flexibility and Team Collaboration," 2009 Second International Conference on Computer and Electrical Engineering, 153-157, 2009.

[15] Masrek, M. N., Jamaludin, A. \& Hashim, D. M. "Determinants of Strategic Utilization of Information Systems: A Conceptual Framework," Journal of Software, 4(6), 591-598, 2009.

[16] Masrek, M. N. \& Jusoff, K. "The effect of information technology infrastructure flexibility on intranet effectiveness," Computer and InformationScience, 2 (2), 57-67, 2009.

[17] Zainon, N. \& Salleh, H. "Dimensions of information technology infrastructure flexibility in improving management efficacy of construction industry perspective: A conceptual study," African Journal of Business Management, 5 (17), 7248-7257, 2011.

[18] Jamaludin, A. "Penggunaan strategik sumber maklumat (PSSM)", Unpublished thesis. Universiti Sains Malaysia (USM), 1996.

[19] DeLone, W. H., \& McLean, E. R. "Information systems success: The quest for the dependent variable," Information Systems Research, 3(1), 60-95, 1992.

[20] DeLone, W. H., \& McLean, E. R. "The Delone and Mclean model of information systems success: A ten-year update.," Journal of Management Information Systems, 19(4), 9-30, 2003.

[21] Basahel, A. \& Irani, Z. "Examining the strategic benefits of information systems: a global case study", European, Mediterranean \& Middle Eastern Conference on Information Systems 2010 (EMCIS2010), April 12-13 2010, Abu Dhabi, UAE, 2010.

[22] King, W. R. \& Sabherwal, R. "The factors affecting strategic information systems applications: An empirical assessment," Information \& Management, 23, 217-235, 1992.

[23] Munusamy, J. \& Chelliah, S. "An investigation of impact of service strategy on customer satisfaction in the budget airline industry in malaysia: a case study of air asia," Contemporary Marketing Review, 1(1), 113,2011

[24] Salleh, R. Che Ahmat, N. \& Radzi, S. "Room Internet Services (RIS) Attributes and Customer Purchase Intention." Retrieved from http://www.ftms.edu.my/ascent2014/BM/15.pdf on 28 August 2014, 2014.

[25] Xia, W. \& King, W. R. "Determinants of Organizational IT Infrastructure Capabilities:An Empirical Study,” 2002.

[26] Davenport, T. and Linder, J. "Information management infrastructure: The new competitive weapon," Proceedings of the Twenty Seventh Hawaii International Conference on System Sciences. IV, 885 896, 1994.

[27] Chanopas, A., Krairit, D. \& Khang, D. B. "Managing information technology infrastructure: a new flexibility framework," Manage Res News, 29(10), 632-651, 2006.

[28] Chung, S. H., Rainer, R. K. Jr. \& Lewis, B. R. "The impact of information technology infrastructure flexibility on strategic alignment and applications implementation," Communications of the Association for Information Systems, 11, 191-206, 2003.

[29] Zhang, J., Li, H. \& Ziegelmayer, J. "Resource or capability?A dissection of SMEs' IT infrastructure flexibility and its relationship with it responsiveness," Journal of Computer Information Systems, 46-53, 2009.

[30] Bush, A. A., Tiwana, A. \& Rai, A. "Complementarities Between Product Design Modularity and IT Infrastructure Flexibility in ITEnabled Supply Chains," IEEE Transactions on Engineering Management, 57(2), 240-254, 2010. 